\title{
Use of traditional medicine among type 2 diabetic Libyans
}

Sana Taher Ashur', Shamsul Azhar Shah', Soad Bosseri ${ }^{2}$ and Khadijah Shamsuddin ${ }^{1}$

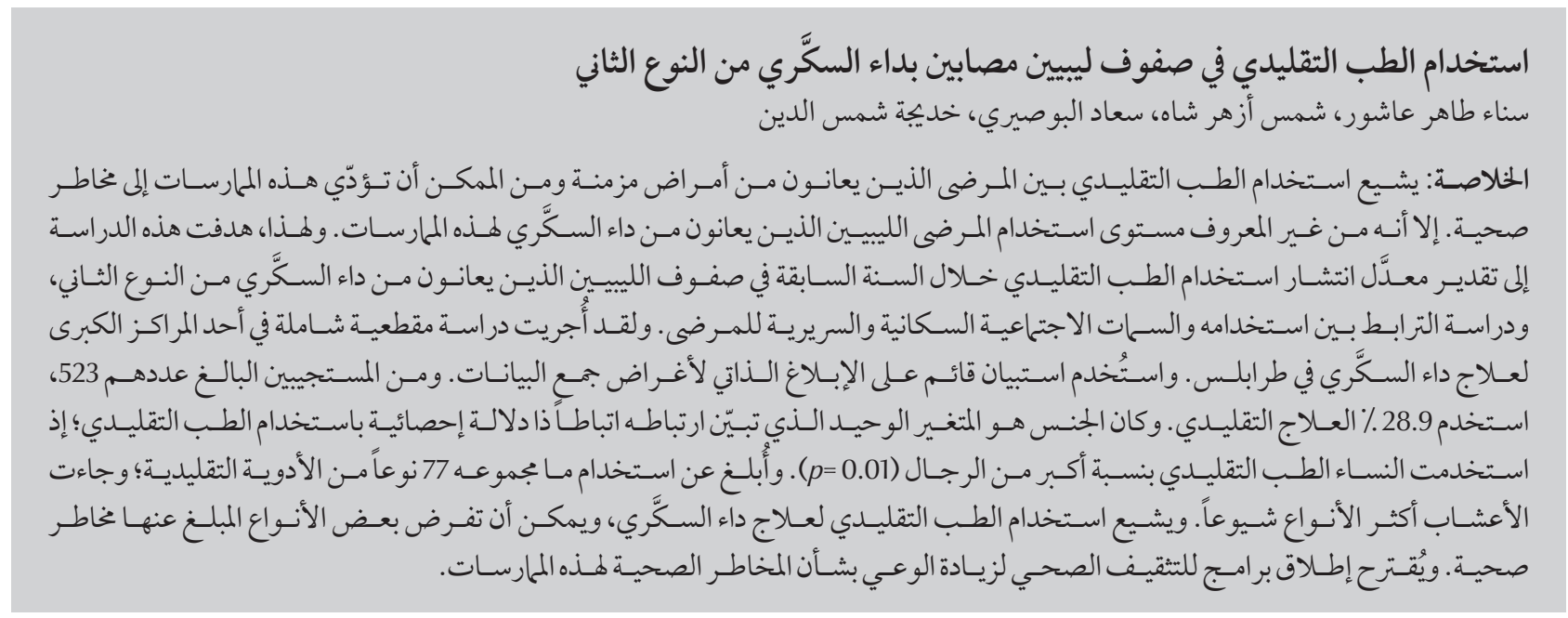

ABSTRACT The use of traditional medicines is common among patients with chronic illnesses and this practice might pose health risks. The use among Libyan patients with diabetes is unknown. Therefore, this study aimed to estimate the prevalence of traditional medicine use in the previous year among Libyans with type 2 diabetes and to examine the association between its use and sociodemographic and clinical characteristics of the patients. A cross-sectional study was conducted at a large diabetes centre in Tripoli. A self-reported questionnaire was used for data collection. Of the 523 respondents, $28.9 \%$ used traditional remedies. Sex was the only variable significantly associated with traditional medicine use; more women used traditional medicines $(P=0.01)$. A total of 77 traditional medicine items were reported to be used, of which herbs were the most common. The use of traditional medicine for diabetes is prevalent and some of the reported items could pose health risks. Health education programmes are suggested to raise the awareness of the health risks of this practice.

\section{Utilisation de la médecine traditionnelle chez des patients libyens atteints de diabète de type 2}

RÉSUMÉ L'utilisation à la médecine traditionnelle est courante parmi les patients souffrant de maladies chroniques et cette pratique peut entraîner des risques pour la santé. On ignore dans quelle mesure les patients diabétiques libyens y ont recours. La présente étude avait pour objectif d'estimer la prévalence de l'utilisation de la médecine traditionnelle au cours de l'année précédente chez des patients libyens atteints de diabète de type 2, ainsi que d'examiner l'association entre cette utilisation et les caractéristiques socio-démographiques et cliniques des patients. Une étude transversale a été conduite dans un grand centre de traitement du diabète à Tripoli. Un questionnaire auto-déclaré a été utilisé pour la collecte de données. Sur les 523 répondants, 28,9\% prenaient des remèdes traditionnels. Le sexe des individus était la seule variable associée de façon significative à I'utilisation de la médecine traditionnelle, un plus grand nombre de femmes y ayant recours $(p=0,01)$. Un total de 77 produits de médecine traditionnelle ont été déclarés, les plus courants étant les plantes. L'utilisation de la médecine traditionnelle pour traiter le diabète est prévalente, et certains des produits rapportés peuvent constituer des risques pour la santé. Il est suggéré de mettre au point des programmes d'éducation sanitaire afin de sensibiliser la population aux risques que cette pratique représente pour la santé.

${ }^{'}$ Department of Community Health, Universiti Kebangsaan Malaysia Medical Centre, Kuala Lumpur, Malaysia (Correspondence to: S. T. Ashur: rsana04@yahoo.com). ${ }^{2}$ National Centre for Diabetes and Endocrinology, Tripoli, Libya.

Received: 22/09/15; accepted: 22/05/16 


\section{Introduction}

The use of traditional medicine is prevalent among patients with chronic health problems $(1,2)$, including diabetes (1-6). A review of traditional medicine use among diabetes populations showed that the prevalence of traditional medicine usage ranged from $17 \%$ to $72.8 \%$ (7). Furthermore, a study in the United States of America found that diabetes was an independent predictor of traditional medicine use (8).

Nutritional supplements, herbs and spiritual practices are among the most commonly used types of traditional medicine used by people with diabetes (7). However, popular traditional medicine types vary across culturally different populations. While traditional Chinese medicines $(5,9)$ and acupuncture $(5)$ are commonly reported to be used by people with diabetes in some Asian countries, they are not popular in the Arab countries where the use of herbal treatments is more prevalent $(10,11)$. Identifying the traditional medicine items used by the patients is important. Although some types of traditional medicine, such as olive leaves (Olea europaea), could possess therapeutic effects (12), there is very little evidence on the safety and effectiveness of many other traditional medicine items. For instance, herbal preparations may have toxic components or be contaminated with some possibly harmful agents (13).

Identifying the factors that drive patients to use traditional medicine is also important. In this context, several studies have examined the influence of sociodemographic and clinical characteristics of diabetes patients on traditional medicine use $(4,8,14)$. Moreover, a review of traditional medicine use among diabetic populations has indicated that some sociodemographic and clinical factors are associated with greater use of traditional medicine (7). Although many of these factors are not modifiable, such research could help to recognize groups that are more likely to use traditional medicine to be targeted by educational programmes.

In the Arab world, traditional medicine is deeply rooted and its use has been known for hundreds of years. A systematic review of the use of Arab traditional medicine in the Eastern Mediterranean Region has highlighted the popularity of such treatments in the Region (15). Furthermore, several Islamic-based therapies are known in Arab settings. These include practices like al-hijama (wet cupping), and al-ruqyah, which is an Islamic-based spiritual practice usually done by reciting some verses from the Quran or dua (supplications) from the sunnah. Correspondingly, prevalent use of traditional medicine by diabetes patients has been reported in some Arab countries (16-18). The Middle East and North Africa region has the highest estimate rate of diabetes in the world (19). Given these factors, it is important to study the use of traditional medicine for diabetes in these populations.

This study aimed to examine the prevalence of the use of traditional medicine for diabetes among Libyans with type 2 diabetes. The prevalence of traditional medicine use for diabetes in the previous year was estimated and the influence of selected sociodemographic and clinical characteristics on this behaviour was examined. The study also explored the commonly used traditional medicine items for diabetes, and the traditional medicine providers and other sources of traditional medicine.

\section{Methods}

\section{Research setting and respondents}

A cross-sectional survey of patients with type 2 diabetes at the National Centre for Diabetes and Endocrinology in Tripoli, Libya, was undertaken between October and December 2013. A total of 523 outpatients completed the survey. Eligible patients were Libyans, aged
18 years and above, who had at least a 1 -year history of type 2 diabetes mellitus and had been placed on diabetes medication. Only those who were able to read and write in Arabic and had no cognitive or visual impairment that might interfere with the self-completion of the questionnaire were included. Pregnant women were also excluded. This study was approved by the Universiti Kebangsaan Malaysia Research and Ethics Committee and the management of the National Centre for Diabetes and Endocrinology. Participation was voluntary, and informed consent was obtained from those who agreed to participate.

\section{Measures}

A self-reporting questionnaire in Arabic was used for data collection. Information was collected on sociodemographic and clinical characteristics and traditional medicine use. The sociodemographic characteristics were: age, sex, marital status, education, employment and income. The clinical characteristics were: duration of diabetes, diabetes medication, presence of comorbidity and glycaemic control status. The information on clinical characteristics was based on self-reporting of the most recent (within 3 months) glycosylated haemoglobin (HbAlc) result, which was verified by checking the most recent laboratory tests brought by the patient. Marital status was defined as unmarried (single, divorced, widowed) and married. Education status was based on the last formal educational achievement and categorized as primary, secondary and university/higher education. $\mathrm{Pa}$ tients were categorized as employed or unemployed (unemployed, housewife or retired) based on their reported employment status. Income was defined as low if the average monthly income was $\leq 600$ Libyan dinars, and moderate to high if the income was $>600$ Libyan dinars. Patients were categorized based on their current diabetes medication into oral medication group, which 
included patients who were on oral hypoglycaemic agents only, and insulintreated group, which included those who were on insulin (with or without oral medication). Glycaemic control status was based on the HbAlc level and categorized as good if the HbAlc level was $<7 \%$ (20) and poor if HbAlc was $\geq 7 \%$. Comorbidity was defined as the self-reported presence or absence of chronic disease(s) other than type 2 diabetes mellitus; this variable was categorized as absent if type 2 diabetes mellitus was the only chronic disease the patient had, and present if the patient reported the presence of one or more chronic disease(s) other than type 2 diabetes mellitus.

Aset of questionswas used to explore the use of traditional medicine. Two questions were used to measure the frequency of traditional medicine use for diabetes, focusing first on "ever use", and "previous 1-year use" $(17,21)$. For each of these 2 questions, respondents were required to choose one response on a 5-point Likert scale, ranging from never to always. Never or rare responses were coded as 0 and defined as non-users, while sometimes, often or always were coded as 1 and defined as traditional medicine users. Following their answer about the frequency of traditional medicine use for diabetes in the previous 1 year, the respondents were required to indicate the traditional medicine items they had used for diabetes from a list of traditional medicine items that was constructed based on a literature review. An open-ended question was added at the end of the list to find out whether there were any other traditional medicine items being used for diabetes that were not suggested in the list. The last 2 questions in the questionnaire were about visits to traditional medicine providers and other traditional medicine sources for diabetes. Respondents were asked to report whether they had visited any traditional medicine provider for diabetes and the type of provider(s). Finally, the respondents were asked about their other sources of traditional medicines.

\section{Data analysis}

Data were analysed using SPSS, version 22. Frequencies and percentages were used to summarize categorical data, while means and standard deviations as well as ranges were used for continuous data. Bivariate associations between the use of traditional medicine for diabetes in the previous 1 year and sociodemographic and clinical characteristics were examined using the $\chi^{2}$ test and Student $t$-test. A $P$-value $<0.05$ was considered statistically significance.

\section{Results}

A total of 523 outpatients completed the survey. As shown in Table 1, the average age of the respondents was 54.43 (SD 10.03) years and 58.9\% were women. More than the half of the respondents had had diabetes for $\leq 9$ years $(59.7 \%)$ and $62.0 \%$ were on insulin, either alone or combined with oral diabetes medications. Data on glycosylated haemoglobin was available for only 478 respondents; of these, $69.6 \%$ had poor glycaemic control.

The prevalence of traditional medicine use for diabetes in the previous one year was $28.9 \%$. There was no statistically significant difference in age between traditional medicine users and non-users. A higher prevalence of traditional medicine use was seen among women (33.1\%) than men (22.8\%), and a statistically significant association $\left(\chi^{2}=6.574, P=0.01\right)$. The prevalence of traditional medicine use was higher among those who: were unmarried, had a lower education level, were employed and had a lower income, but the differences were not statistically significant. A higher prevalence of traditional medicine use was also found among the respondents who had had diabetes for $>9$ years, those who were on oral medications only and those who reported having comorbidity, but again the differences were not statistically significant. Traditional medicine use was also higher among those with good glycaemic control group (33.3\%) than those with poor glycaemic control (26.9\%) but this was not statistically significant.

A total of 77 traditional medicine items used for diabetes were identified and grouped as herbs, home remedies and practices (Table 2). The herbal group included 41 items and among these luban dakar (olibanum, Boswellia spp.) (19.3\%), olive leaves (11.9\%) and al-habasawda (blackseeds,Nigellasativa) (7.6\%) were the three most commonly reported herbs used. Home remedies included 30 items and among these green tea (Camellia sinensis) (26.6\%), onion (Allium cepa) (18.9\%) and garlic (Allium sativum) (16.8\%) were the three most commonly used items. Only 6 practices were identified; the three most commonly reported practices were: prayers (29.8\%), al-hijama or wet cupping $(14.3 \%)$ and al-ruqyah by reciting verses from the Quran (9.6\%). The total number of items used per respondent ranged between zero and 24 items, with a mean of 3.25 (SD 4.64) items.

Table 3 shows the pattern of traditional medicine use for diabetes. The prevalence of ever use of traditional medicine for diabetes was $36.5 \%$, while the prevalence of traditional medicine use for diabetes in the previous 1 year was $28.9 \%$. The table also shows the type of traditional medicine used, regardless of the frequency of use. The prevalence of the use of at least a single traditional medicine item of any of the 3 types (herbs, home remedies or practices) was 59.5\%, while the prevalence of use of at least 1 traditional medicine item from each type was $22.0 \%$. The prevalence of the types of traditional medicine use were: $8.2 \%$ each for herbs only ( 1 herb or more) and home remedies only ( 1 or more), $4.4 \%$ for practices only ( 1 or more), $8.8 \%$ for at least 1 herb and 1 home remedy, $0.6 \%$ for at least 1 


\begin{tabular}{|c|c|c|c|c|c|}
\hline \multirow[t]{2}{*}{ Characteristic } & All & User $^{1}$ & Non-user & $x^{2}$ & $P$-value \\
\hline & No. (\%) & No. $(\%)$ & No.(\%) & & \\
\hline \multicolumn{6}{|l|}{ Sociodemographic } \\
\hline Age (years) [Mean (SD)] & $54.43(10.03)$ & $53.52(9.99)$ & $54.80(10.04)$ & $1.325^{2}$ & 0.186 \\
\hline \multicolumn{6}{|l|}{ Sex } \\
\hline Male & $215(41.1)$ & $49(22.8)$ & $166(77.2)$ & & \\
\hline Female & 308 (58.9) & $102(33.1)$ & $206(66.9)$ & 6.574 & 0.010 \\
\hline \multicolumn{6}{|l|}{ Marital status } \\
\hline Unmarried & $121(23.1)$ & $43(35.5)$ & $78(64.5)$ & & \\
\hline Married & 402 (76.9) & 108 (26.9) & $294(73.1)$ & 3.406 & 0.065 \\
\hline \multicolumn{6}{|l|}{ Education } \\
\hline Primary & $304(58.1)$ & 91 (29.9) & $213(70.1)$ & & \\
\hline Secondary & $155(29.6)$ & $44(28.4)$ & $111(71.6)$ & & \\
\hline University and higher & $64(12.2)$ & $16(25.0)$ & $48(75.0)$ & 0.652 & 0.722 \\
\hline \multicolumn{6}{|l|}{ Employment } \\
\hline Employed & $142(27.2)$ & $43(30.3)$ & $99(69.7)$ & & \\
\hline Unemployed & $381(72.8)$ & $108(28.3)$ & $273(71.7)$ & 0.189 & 0.664 \\
\hline \multicolumn{6}{|l|}{ Income $(L D)^{3}$} \\
\hline Low & $394(75.3)$ & $119(30.2)$ & $275(69.8)$ & & \\
\hline Moderate-high & $129(24.7)$ & $32(24.8)$ & $97(75.2)$ & 1.378 & 0.240 \\
\hline \multicolumn{6}{|l|}{ Clinical } \\
\hline \multicolumn{6}{|l|}{ Duration of diabetes (years) } \\
\hline$\leq 9$ & $312(59.7)$ & $86(27.6)$ & $226(72.4)$ & 0.644 & 0.422 \\
\hline 9 & $211(40.3)$ & $65(30.8)$ & $146(69.2)$ & & \\
\hline \multicolumn{6}{|l|}{ Medications } \\
\hline Oral medications & $199(38.0)$ & $61(30.7)$ & $138(69.3)$ & & \\
\hline Insulin \pm oral medications & $324(62.0)$ & $90(27.8)$ & $234(72.2)$ & 0.496 & 0.481 \\
\hline \multicolumn{6}{|l|}{ Glycaemic control $(n=478)^{4}$} \\
\hline Poor & $364(69.6)$ & $98(26.9)$ & $266(73.1)$ & & \\
\hline Good & $114(21.8)$ & $38(33.3)$ & $76(66.7)$ & 1.752 & 0.186 \\
\hline \multicolumn{6}{|l|}{ Presence of comorbidity } \\
\hline Absent & $215(41.1)$ & $60(27.9)$ & $155(72.1)$ & & \\
\hline Present & $308(58.9)$ & 91 (29.5) & $217(70.5)$ & 0.166 & 0.684 \\
\hline
\end{tabular}

'Used traditional medicine for diabetes in the previous 12 months.

${ }^{2}$ Student $t$-test

${ }^{3} L D=$ Libyan dinars $(1.32 L D=U S \$ 1$, at the time of the study).

${ }^{4}$ There were only 478 respondents for whom glycaemic control data were available.

$S D=$ standard deviation

herb and 1 practice, and $7.3 \%$ for at least 1 home remedy and 1 practice. Only $18.9 \%$ of the respondents reported visiting traditional medicine providers to seek remedies for diabetes, with spice dealers given as the most common providers (14.1\%). However, 20.3\% of the respondents gave other sources of acquiring traditional medicine for diabetes: the 3 most common sources were supermarkets (16.1\%), the land (gardens, farms or mountains) (2.7\%) and family members or friends (1.7\%).

\section{Discussion}

This study investigated the use of traditional medicine for diabetes among Libyans with type 2 diabetes mellitus attending a large diabetes centre in Tripoli. Female patients were more represented in our sample than males. One explanation could be that women are less reluctant to participate and disclose information about their use of traditional medicine compared to men. However, the predominance of females over males was probably merely a reflection of the sex pattern of type 2 diabetes 


\begin{tabular}{|c|c|}
\hline Traditional medicine used $(n=77)$ & No. (\%) \\
\hline \multicolumn{2}{|c|}{ Total traditional medicine items used per respondent } \\
\hline Range & $0-24$ \\
\hline Mean (SD) & $3.25(4.64)$ \\
\hline \multicolumn{2}{|l|}{ Herbs (41 items) } \\
\hline Olibanum (Boswellia spp.) & $101(19.3)$ \\
\hline Olive leaves (Olea europaea) & $62(11.9)$ \\
\hline Black seeds (Nigella sativa) & $40(7.6)$ \\
\hline Sour pomegranate (Punica granatum) & $35(6.7)$ \\
\hline Lupine seeds (Lupinus spp.) & $24(4.6)$ \\
\hline Commercial herbal tea & $17(3.3)$ \\
\hline Unknown folk medicine & $17(3.3)$ \\
\hline Helteet (Ferula assa-foetida) & $12(2.3)$ \\
\hline Chinese herbs & $10(1.9)$ \\
\hline Nettle (Urtica dioica) & $9(1.7)$ \\
\hline Colocynth (Citrullus colocynthis) & $9(1.7)$ \\
\hline Jaadah or Shangoura (Germander spp.) & $8(1.5)$ \\
\hline Harmal (Rhazya Stricta) & $7(1.3)$ \\
\hline Aloe (Aloe vera) & $7(1.3)$ \\
\hline Marjoram (Origanum majorana) & $5(1.0)$ \\
\hline Garden Cress (Lepidium sativum) & $4(0.8)$ \\
\hline Flax seeds (Linum usitatissimum) & $3(0.6)$ \\
\hline Blueberry leaves (Cyanococcus) & $3(0.6)$ \\
\hline Wormwood (Artemisia absenthium) & $3(0.6)$ \\
\hline Bitter aloe (Aloe ferox) & $2(0.4)$ \\
\hline Sage (Salvia officinalis) & $2(0.4)$ \\
\hline Lemon verbena (Verbena officinalis) & $1(0.2)$ \\
\hline Myrrh (Commiphora myrrha) & $1(0.2)$ \\
\hline Bitter almond (Prunus dulcis) & $1(0.2)$ \\
\hline Psyllium (Plantago psyllium) & $1(0.2)$ \\
\hline Costus Indian (Saussurea costus) & $1(0.2)$ \\
\hline Tamer Mur (Brosimum spp.) & $1(0.2)$ \\
\hline Al-Adeed (Launaea mucronata) & $1(0.2)$ \\
\hline Arugula (Eruca sativa) & $1(0.2)$ \\
\hline Myrtle (Myrtus communis) & $1(0.2)$ \\
\hline White horehound (Marrubium vulgare) & $1(0.2)$ \\
\hline Juniper (Juniperus spp.) & $1(0.2)$ \\
\hline Loquat leaves (Eriobotrya japonica) & $1(0.2)$ \\
\hline Doum (Hyphaene thebaica)) & $1(0.2)$ \\
\hline Common rue (Ruta graveolens) & $1(0.2)$ \\
\hline Ziziphus (Ziziphus mauritiana) & $1(0.2)$ \\
\hline Orris Root (Iris germanica) & $1(0.2)$ \\
\hline Lentisco (Pistacia lentiscus) & $1(0.2)$ \\
\hline Rock cherry (Prunus mahaleb) & $1(0.2)$ \\
\hline Tamarisk (Tamarix) & $1(0.2)$ \\
\hline \multicolumn{2}{|l|}{ Home remedies (30 items) } \\
\hline Green tea (Camellia sinensis) & $139(26.6)$ \\
\hline Onion (Allium сера) & 99 (18.9) \\
\hline
\end{tabular}

mellitus in Libya. According to a study of the epidemiological profile of type 2 diabetes mellitus in a clinical setting, there were significantly more females with type 2 diabetes mellitus than males (22). As reported in the present study, several other studies among people with diabetes in Libya have shown a preponderance of females over males (23-25).

The prevalence of traditional medicine use for diabetes in the previous year among our Libyan sample was high $(28.9 \%)$. This prevalence is higher than the rates reported among diabetic patients in some other Arab settings. For instance, the prevalence of herbal use for diabetes among Iraqi patients was $17.3 \%$ (26); in Lebanon, a clinic-based study reported a rate of traditional medicine use in the past 12 months of $21 \%$ (14). In Tunisia, Libya's immediate neighbour, a clinic-based study among diabetes patients reported $23 \%$ of patients used herbal remedies for blood sugar control (11). However, higher figures were found among diabetic patients in other Arab countries, such as 41.7\% in Egypt (27), 51.9\% in Palestine (10), 63\% in Bahrain (16) and $54.8 \%$ in Morocco (28). Generally, the differences in the definition of traditional medicine use across studies prevent precise comparisons of traditional medicine use rates.

Several traditional medicine items used by Libyans for diabetes were identified, and many of them matched those reported in other Arab settings $(11,17,26,29)$. A total of 77 traditional medicine items were reported and categorized into herbs, home remedies and practices. Herbs were the most common type of traditional medicine used. Of concern was the fact that some items have questionable effectiveness and safety. The observed rates of use of the majority of herbs were low, however, the actual rates might be higher considering that underreporting may have occurred. Therefore, clinicians should be encouraged to ask their patients specifically about the use of traditional medicine 


\begin{tabular}{|c|c|}
\hline \multicolumn{2}{|c|}{ Table 2 Items of traditional medicine used for diabetes $(n=523)$ (concluded) } \\
\hline Traditional medicine used $(n=77)$ & No. $(\%)$ \\
\hline Garlic (Allium sativum) & $88(16.8)$ \\
\hline Fenugreek (Trigonella foenum-graecum) & $80(15.3)$ \\
\hline Ginger (Zingiber officinale) & $78(14.9)$ \\
\hline Lemon (Citrus $x$ limon) & $72(13.8)$ \\
\hline Thyme (Thymus vulgaris) & $62(11.9)$ \\
\hline Honey & $61(11.7)$ \\
\hline Parsley (Petroselinum crispum) & $61(11.7)$ \\
\hline Coriander (Coriandrum sativum) & $44(8.4)$ \\
\hline Dill (Anethum graveolens) & $43(8.2)$ \\
\hline Cumin (Cuminicum cyminum) & $32(6.1)$ \\
\hline Cloves (Syzgium aromaticum) & $31(5.9)$ \\
\hline Vinegar & $23(4.4)$ \\
\hline Anise (Pimpinella anisum) & $22(4.2)$ \\
\hline Cinnamon (Cinnamomum verum) & $13(2.5)$ \\
\hline Rosemary (Rosmarinus officinalis) & $4(0.8)$ \\
\hline Barley (Hordeum vulgare) & $3(0.6)$ \\
\hline Sesame (Sesamum indicum) & $2(0.4)$ \\
\hline Wheat (Triticum spp.) & $2(0.4)$ \\
\hline Mint (Mentha spp.) & $2(0.4)$ \\
\hline Camomile (Chamaemelum nobile) & $1(0.2)$ \\
\hline Fennel (Foeniculum vulgare) & $1(0.2)$ \\
\hline Roselle (Hibiscus sabdariffa) & $1(0.2)$ \\
\hline Celery (Apium graveolens) & $1(0.2)$ \\
\hline Eggplant (Solanum melongena) & $1(0.2)$ \\
\hline Grapefruit (Citrus x paradisi) & $1(0.2)$ \\
\hline Lentil (Lens culinaris) & $1(0.2)$ \\
\hline Kiwi (Actinidia deliciosa) & $1(0.2)$ \\
\hline \multicolumn{2}{|l|}{ Practices (6 practices) } \\
\hline Prayers & $156(29.8)$ \\
\hline Al-hijama (wet cupping) & $75(14.3)$ \\
\hline Ruqyah (recitation) with the Quran & $50(9.6)$ \\
\hline Ruqyah water or oil & $28(5.4)$ \\
\hline Acupuncture & $8(1.5)$ \\
\hline Cautery & $5(1.0)$ \\
\hline
\end{tabular}

$S D=$ standard deviation .

items when taking their medical history. This is important because some herbs could have a hypoglycaemic effect that might act synergistically with diabetes medications. Respondents also reported some spiritual practices such as prayers and al-ruqyah. In addition, the respondents reported the use of wet cupping, which involves making incisions on the skin (30). Since diabetes patients, especially those with uncontrolled diabetes, are at greater traditional medicine items. A few patients reported that sheikhs were among their traditional medicine providers. Whilst sheikh is the term used for an Islamic jurist, it is also used among the public to refer to non-professionals such as traditional healers or others who claim to have the ability to treat ailments. The three most common "other sources" of traditional medicine were supermarkets, the land (gardens, farms or mountains) and family members or friends. This raises concerns about the health risks that could be associated with obtaining traditional medicine from non-professional persons or through non-approved outlets. The findings of our study are similar to those of a study in Morocco in which the land and herbalists were the most common sources of traditional medicine, while friends and family were also important sources of information on these remedies (28). A smaller proportion of the respondents reported street sellers as their source for diabetes remedies, which further emphasizes the need for educating patients about the risks of using remedies from unknown sources to cope with their illness.

Among all sociodemographic and clinical factors studied, only sex had a statistically significant association with traditional medicine use for diabetes, with more females using traditional medicine than males. This association could have been driven by some latent factors, such as a higher perception of the effectiveness of traditional medicine among females, which could be a subject for further research. Similarly, a study from Saudi Arabia reported significantly higher traditional medicine use among females (17). Likewise, a higher rate of traditional medicine use was reported among women with diabetes in Palestine and Morocco, although no statistically significance associations were found $(10,28)$. Although not quite significant $(P=0.065)$ there was a lower rate of traditional medicine use among married patients compared to 


\begin{tabular}{|c|c|c|}
\hline \multirow[t]{2}{*}{ Traditional medicine use for diabetes } & User & Non-user \\
\hline & No. (\%) & No. $(\%)$ \\
\hline \multicolumn{3}{|l|}{ Use status based on frequency } \\
\hline Ever use & $191(36.5)$ & $332(63.5)$ \\
\hline Previous 1 year & $151(28.9)$ & $372(71.1)$ \\
\hline \multicolumn{3}{|l|}{ Use status based on traditional medicine type } \\
\hline At least one item from any group & $311(59.5)$ & $212(40.5)$ \\
\hline Only herbs ( $\geq 1$ ) & $43(8.2)$ & \\
\hline Only home remedies ( $\geq 1$ ) & $43(8.2)$ & \\
\hline Only practices $(\geq 1)$ & $23(4.4)$ & \\
\hline$\geq 1$ herb and $\geq 1$ home remedy & $46(8.8)$ & \\
\hline$\geq 1$ herb and $\geq 1$ practice & $3(0.6)$ & \\
\hline$\geq 1$ home remedy and $\geq 1$ practice & $38(7.3)$ & \\
\hline At least 1 item from each group & $115(22.0)$ & \\
\hline \multicolumn{3}{|l|}{ Providers and other sources ${ }^{a}$} \\
\hline Traditional medicine provider & 99 (18.9) & \\
\hline Spice dealer & $74(14.1)$ & \\
\hline Licensed traditional medicine centre & $24(4.6)$ & \\
\hline Sheikh & $12(2.3)$ & \\
\hline Not specified & $3(0.6)$ & \\
\hline Other & $106(20.3)$ & \\
\hline Supermarkets & $84(16.1)$ & \\
\hline Land (gardens, farms or mountains) & $14(2.7)$ & \\
\hline Family or friends & $9(1.7)$ & \\
\hline Herbal pharmacy & $3(0.6)$ & \\
\hline Non-professional person for al-hijama (wet cupping) & $3(0.6)$ & \\
\hline Street sellers & $1(0.2)$ & \\
\hline Not specified & $7(1.3)$ & \\
\hline
\end{tabular}

${ }^{a}$ The total across the traditional medicine providers was greater than 99 and the total across the other sources was greater than 106, as some respondents indicated more than one provider and other source.

unmarried patients. This finding might have been driven by factors such as spousal influences, and further research may be warranted to investigate the role of spouses and if their beliefs about traditional medicine effectiveness and safety could influence such use by their partners.

Overall, the findings of our study have shown that the sociodemographic and clinical factors have a limited influence on the use of traditional medicine to cope with diabetes. These findings corroborate the findings of some other studies in other Arab populations. For instance, a study among diabetes patients in Saudi Arabia did not report significant associations between sociodemographic factors and the use of herbs (29), and, except for residence, herbal use by Palestinian diabetic patients was not shown to be influenced by sociodemographic or clinical factors (10). Therefore, there is a need to investigate other factors that might have a more important role in driving patients to use traditional medicine to cope with their condition. Factors such as cultural beliefs (5) and perceptions about the effectiveness of diabetes medications could potentially have a more important role as determinants of this behaviour.

There are certain limitations to our study. Issues associated with selfreporting, such as recall bias and reluctance to report traditional medicine use, might have reduced the real prevalence of traditional medicine use. Moreover, exclusion of illiterate diabetes patients prevents inferences on traditional medicine use being made among this group. In addition, this study involved a single diabetic facility in Tripoli; therefore, the generalizability of the findings is limited and general inferences on traditional medicine use among all Libyans with type 2 diabetes mellitus cannot be made. Although much remains to be done, the findings have contributed to enhancing knowledge on traditional medicine use for diabetes, and will be useful for health care policy-makers and diabetes care practice in Libya. 


\section{Conclusion}

The findings from this study show a considerable prevalence of traditional medicine use for diabetes in the Libyan setting. Some of the reported traditional medicine items are questionable in terms of effectiveness and safety. Therefore, clinicians should be encouraged to ask their patients about traditional medicine use and educate them about the possible health risks of this practice. Furthermore, given the many different traditional medicine items reported to be used, clinical trials are warranted to investigate the effectiveness and safety of many these traditional medicine items.

\section{Acknowledgements}

We would like to thank the Universiti Kebangsaan Malaysia for supporting this work and the members of staff of the National Centre for Diabetes and Endocrinology in Libya for their cooperation. Funding: Universiti Kebangsaan Malaysia under the project FF-2013-298.

Competing interests: None declared.

\section{References}

1. Hasan SS, Ahmed SI, Bukhari NI, Loon WC. Use of complementary and alternative medicine among patients with chronic diseases at outpatient clinics. Complement Ther Clin Pract. 2009;15(3):152-7.

2. Mollaoğlu M, Aciyurt A. Use of complementary and alternative medicine among patients with chronic diseases. Acta Clin Croat. 2013;52(2):181-8.

3. Chang HY, Wallis M, Tiralongo E. Use of complementary and alternative medicine among people with type 2 diabetes in Taiwan: A cross-sectional survey. Evid Based Complement Alternat Med. 2011. pii: 983792. doi: 10.1155/2011/983792.

4. Manya K, Champion B, Dunning T. The use of complementary and alternative medicine among people living with diabetes in Sydney. BMC Complement Altern Med. 2012;12(2): doi: 10.1186/1472-6882-12-2.

5. Lee GB, Charn TC, Chew ZH, Ng TPC. Complementary and alternative medicine use in patients with chronic diseases in primary care is associated with perceived quality of care and cultural beliefs. Fam Pract. 2004;21(6):654-60.

6. Hasan SS, Loon WC, Ahmadi K, Ahmed SI, Bukhari NI. Reasons, perceived efficacy and factors associated with complementary and alternative medicine use among Malaysian patients with diabetes mellitus. Br J Diabetes Vasc Dis. 2011;11(2):92-8.

7. Chang HY, Wallis M, Tiralongo E. Use of complementary and alternative medicine among people living with diabetes: literature review. J Adv Nurs. 2007;58(4):307-19.

8. Egede LE, Ye X, Zheng D, Silverstein MD. The prevalence and pattern of complementary and alternative medicine use in individuals with diabetes. Diabetes Care. 2002;25(2):324-9.

9. Huri HZ, Lian GTP, Hussain S, Pendek R, Widodo RT. A survey amongst Complementary Alternative Medicine (CAM) users with type 2 diabetes. Int J Diabetes Metab. 2009;17(1):9-15.

10. Ali-Shtayeh MS, Jamous RM, Jamous RM. Complementary and alternative medicine use amongst Palestinian diabetic patients. Complement Ther Clin Pract. 2012;18(1):16-21. 10.1016/j.ctcp.2011.09.001

11. Ben Othman R, Ibrahim H, Mankai A, Abid N, Othmani N, Jenhani N, et al. Use of hypoglycemic plants by Tunisian diabetic patients. Alexandria Journal of Medicine. 2013;49(3):261-4.

12. Wainstein J, Ganz T, Boaz M, Bar Dayan Y, Dolev E, Kerem Z, et al. Olive leaf extract as a hypoglycemic agent in both human diabetic subjects and in rats. J Med Food. 2012;15(7):605-10.

13. Hussin $\mathrm{AH}$. Adverse effects of herbs and drug-herbal interactions. Malays J Pharm. 2001;1(2):39-44.

14. Naja F, Mousa D, Alameddine M, Shoaib H, Itani L, Mourad Y. Prevalence and correlates of complementary and alternative medicine use among diabetic patients in Beirut, Lebanon: a cross-sectional study. BMC Complement Altern Med. 2014 Jun 6;14:185. doi: 10.1186/1472-6882-14-185.

15. Azaizeh H, Saad B, Khalil K, Said O. The state of the art of traditional Arab herbal medicine in the Eastern region of the Mediterranean: A review. Evid Based Complement Alternat Med. 2006;3(2):229-35.
16. Khalaf AJ, Whitford DL. The use of complementary and alternative medicine by patients with diabetes mellitus in Bahrain: a cross-sectional study. BMC Complement Altern Med. 2010; 10:35. doi: 19.1186/1472-6882-10-35.

17. Al-Faris EA. The pattern of alternative medicine use among patients attending health centres in a military community in Riyadh. J Family Community Med. 2000;7(2):17-25.

18. Ahmed AM. Alternative versus traditional medicine use among adults: Sharja-United Arab Emirates, 2009. Egypt J Community Med. 2011;29(1):59-71.

19. International Diabetes Federation (IDF). Diabetes atlas 6th edition 2013. Available from: https://www.idf.org/sites/ default/files/EN_6E_Atlas_Full_0.pdf [ cited 12 October 2014]

20. American Diabetes Association. Standards of medical care in diabetes-2013. Diabetes Care. 2013;36:S11-66.

21. Eisenberg DM, Kessler RC, Foster C, Norlock FE, Calkins DR, Delbanco TL. Unconventional medicine in United States- Prevalence, costs and patterns of use. N Engl J Med. 1993;328(4):246-52.

22. Kadiki OA, Roaed RB. Epidemiological and clinical patterns of diabetes in Benghazi, Libyan Arab Jamahiriya. East Mediterr Health J. 1999;5(1):6-13.

23. Roaeid RB, Kablan AA. Profile of diabetes health care at Benghazi Diabetes Centre, Libyan Arab Jamahiriya. East Mediterr Health J. 2007;13(1):168-76.

24. Elkharam WM, Khatri R, Wallymahmed AH, Gee I, Elhisadi T. Knowledge of and adherence to health advice among adults with diabetes in Libya. Ibnosina J Med BS. 2013;5(3):140-7.

25. Elmiladi SA. Fasting and diabetic care during, Ramadan in Libyan people with diabetes in Tripoli diabetes endocrine hospital. Libyan J Med Res. 2014;8:69-75.

26. Al-Asadi JN, Salih N. Herbal remedies use among diabetic patients in Nassyria, Iraq. Middle East Journal of Family Medicine. 2012;10(10):40-6.

27. Khalil SH, Zaki A, Ibrahim AM, El-Moughazi AM, Khater AM, Youssef AM. EL-Sa'ed AT, Rashed EM. Pattern of use of complementary and alternative medicine among type 2 diabetes mellitus patients in Alexandria, Egypt. J Egypt Public Health Assoc. 2013;88(3):137-42.

28. Alami Z, Aynaou H, Alami B, Hdidou Y, Latrech H. Herbal medicines use among diabetic patients in Oriental Morocco. J. Pharmacognosy Phytother. 2015;7(2):9-17.

29. Al-Rowais NA. Herbal medicine in the treatment of diabetes mellitus. Saudi Med J. 2002;23(11):1327-31.

30. El-Wakil A. Observations of the popularity and religious significance of blood-cupping (al-hijama) as an Islamic medicine. Contemporary Islamic Studies. 2011;2: 10.5339/cis.2011.2. 